\title{
MURCIA BAJO LA MIRADA FOTOGRÁFICA DE MARÍA MANZANERA
}

\author{
Laura Cano Martínez.
}

Universidad de Murcia

\section{RESUMEN}

El presente artículo se centra en la visión que tiene María Manzanera de Murcia, valiéndose de la fotografía como medio de conocimiento. En las obras Murcia Verticalia, Murcia Huertana y Murcia, día y noche, perfila una urbe de contrastes en la que subyace la esencia que la distingue. Sus series reflejan un notable proceso de contemplación y un admirable ejercicio de reflexión, ofreciendo una perspectiva singular de la ciudad. La fotógrafa contribuye a sublimar y dignificar la capital a través de su arte, concienciando del valor y conservación de todo lo que la hace única.

Palabras clave: fotografía; Región de Murcia; María Manzanera; ciudad; huerta.

\section{Murcia through photographic look of Maria Manzanera}

\section{ABSTRACT}

This article focuses on vision of Maria Manzanera about Murcia through photography as a means of knowledge. In her works Murcia Verticalia, Murcia Huertana and Murcia, dia y noche, she defines a city full of contrasts where its distinctive essence underlies. Her photographic series reflect significant processes of contemplation and critical thought. Moreover, she offers a unique viewpoint of the capital. The photographer uses her art in order to sublimate and dignify Murcia, raising awareness of its value and the need for preservation remains.

Keywords: photography; Region of Murcia; Maria Manzanera; city; vegetable garden.

Fecha de recepción: 24 de mayo de 2017.

Fecha de aceptación: 7 de marzo de 2018.

Departamento de Historia del Arte. Universidad de Murcia. Campus de La Merced. 30001 MURCIA (España). E-mail: 1.canomartinez@um.es 


\section{INTRODUCCIÓN}

Desde la llegada de la fotografía a España hacia 1839¹, Murcia ha sido inmortalizada por diversos fotógrafos ${ }^{2}$. Entre ellos, cabe destacar César Baroja (fotógrafo de cámara de la Reina Isabel II) por su álbum sobre los edificios más representativos en la década de 1860. Manuel Baroja, pariente del primero, plasma una urbe en proceso de industrialización a través de la instalación de las primitivas líneas férreas en la segunda mitad del siglo XIX. Juan Almagro, capta la ciudad con sus gentes y monumentos históricos, sobresaliendo el reportaje de la riada de Santa Teresa que constituye un testimonio esencial de la Murcia del último tercio del siglo XIX. Francisco Viñes, fotógrafo ambulante, muestra, entre otros eventos, la última ejecución pública realizada en la ciudad en 1896, siendo protagonizada por Josefa Gómez (La Perla). A esta lista se suma el aficionado M. Costa Farinas, quien lega imágenes de la Exposición Nacional celebrada en Murcia en 1900.

Entre los profesionales extranjeros, el galés Charles Clifford (fotógrafo oficial de la reina Isabel II) capta la ciudad engalanada de arquitecturas efímeras para la visita regia en 1862. De procedencia francesa, es Jean Laurent, quien realiza postales y álbumes de la Región, siendo la capital uno de los lugares elegidos para captar escenas costumbristas. En este sentido, habría que tener en cuenta que todas estas imágenes estarían en consonancia con la popularización de tarjetas postales de vistas urbanas y paisajes ${ }^{3}$, tan demandadas desde principios de 1890. En la siguiente centuria, el francés Jean Dieuzaide es uno de los autores que contribuye a enriquecer el patrimonio gráfico de la sociedad murciana de los años cincuenta.

En el siglo XX, según María Manzanera, «hubo en nuestra ciudad un aficionado excepcional que debemos destacar en esta historia fotografía» (Manzanera, 2002a:209), Luis Federico Guirao Girada. Abogado y político, es autor de numerosas vistas de la ciudad y de la huerta del primer cuarto de siglo. Entre las décadas de 1920 y 1930, una de las figuras clave es José Casaú Abellán que capta todo tipo de acontecimientos, siendo considerado por Vázquez Casillas como uno de los «documentalistas más importantes de la Región» (Vázquez Casillas, 2010a:97). Otro importante fotógrafo es Cristóbal Belda Navarro, cuyo archivo conformado por imágenes de carácter histórico-artístico resulta ser de gran valor patrimonial.

1 Según las investigaciones llevadas a cabo por Marie-Loup Sougez, el primer daguerrotipo realizado en España data del 10 de noviembre de 1839 (Barcelona), por lo que podría considerarse esta fecha como referencia a la hora de determinar los orígenes de la fotografía en territorio nacional. En SOUGEZ, M.L. (2006): Historia de la fotografía (10 ed.). Madrid, Cátedra, pp. 212.

2 Para más información véase: MANZANERA, M. (2002): La Imagen Transparente: Comienzos de la fotografía en la ciudad de Murcia, 1840-1920. Murcia, Cajamurcia, Fotoencuentros, pp. 47-297; y VÁZQUEZ CASILLAS, F. (2010): «Viaje a la memoria a través de la fotografía», en Viajeros y fotógrafos de la Historia de Murcia. Taller de Historia del Archivo General. Murcia, Ediciones Tres Fronteras, Consejería de Cultura y Turismo, pp. 87-106.

3 DÍAZ BURGOS, J. M. y ROIG MECA, A. J. (2004): Tarjeta postal: Región de Murcia (exposición). Murcia, Centro Histórico Fotográfico de la Región de Murcia (CEHIFORM). p. 9. 
Dentro del fotoperiodismo desarrollado en Murcia entre las décadas de los años treinta y cincuenta ${ }^{4}$, resaltan los autores Juan López Hernández, quien cubre todo tipo de eventos políticos y socioculturales durante cuatro décadas; y Miguel Herrero Malast, fotógrafo que documenta a la sociedad murciana contemporánea. Según afirma Vázquez Casillas, a finales de los años cincuenta es Tomás Lorente, discípulo de Malast, «quien siga sus pasos como reportero gráfico» (Vázquez Casillas, 2005a:69). En los años sesenta y setenta, destacan dos autores enmarcados en la corriente documental: Juan Orenes, cuya obra es considerada por el mismo fotohistoriador como un «documento social, por lo testimonial» (Vázquez Casillas, 2003a:250) y Ángel Bermejo Luengo, que capta escenas cotidianas desde un punto de vista amable. En la década de 1980, Murcia cuenta con José Hernández Pina, cuya producción se enmarca dentro de la corriente realista; Ángel Fernández Saura, quien realiza fotografía de reportaje de carácter directo durante ese periodo; y Paco Salinas, quien compagina la fotografía de prensa con su trabajo personal. En los años noventa, y dentro del ámbito documental desarrollado en la ciudad de Murcia, alcanzan su máximo desarrollo los profesionales mencionados previamente, ya que vienen trabajando desde los años setenta. A éstos se suman Carlos Moisés García con sus vistas urbanas y paisajes y Juan Ballester que, tal y como anuncia Vázquez Casillas, «se encuentra consolidado como uno de los representantes significativos de la fotografía de esta zona» (Vázquez Casillas, 2005b:189). Tal interés en Murcia como escenario de inspiración se ha prolongado hasta nuestros días, por lo que continúan su labor autores como Ángel Fernández Saura, Juan Manuel Díaz Burgos y Antonio López Mateo, entre otros. A este grupo se añade Gloria Nicolás, quien destaca dentro del ámbito de la prensa utilizando la fotografía directa y el color.

Mención aparte merece María Manzanera, una de las pocas mujeres fotógrafas que participan en el ejercicio fotográfico español con continuidad desde 1970 hasta la actualidad. La artista, que trabaja en solitario y fuera del fotoperiodismo, viene realizando fotografía urbana de diversas ciudades del mundo desde los años ochenta. Sin embargo, es a partir del siglo XXI cuando ofrece una visión de Murcia alejada del imaginario tradicional de panorámicas y representaciones propias de las tarjetas postales. Dentro de su variado archivo fotográfico, hay tres series dedicadas a su ciudad natal: Murcia Verticalia, Murcia Huertana y Murcia, día y noche, obras que se analizan en el presente escrito. En estos trabajos, se revela un lugar rebosante de vida, luz, calidez y dinamismo mediante visiones aparentemente antagónicas. En las cuales, se oponen representaciones urbanas y rurales y lugares anclados en el pasado que se resisten a participar en el devenir de lo urbano.

Manzanera, somete a la ciudad a un ejercicio de observación recogiendo las características que la identifican, deteniéndose en elementos que suelen pasar desapercibidos para el viandante. Para ello, recurre a un proceso de sublimación del que surgen imágenes que desprenden belleza y sensibilidad artística. Al respecto, el cronista oficial de la Región Antonio Botías Saus, afirma que la artífice goza de pública estima por su producción creativa, «reconocimiento que la mayoría de aquellos primeros maestros no tuvieron en Murcia, unas veces por desconocimiento del pueblo y otras por la extendida incultura» (Botías, 2017a:6).

4 Sobre este asunto véase: VÁZQUEZ CASILLAS, F. (2003): «Fotografía en la ciudad de Murcia: de los años treinta a los años cincuenta», en Fotografía en la Región de Murcia. Murcia, Dirección de Proyectos e Iniciativas Culturales, Centro Histórico Fotográfico Región de Murcia, Caja de Ahorros del Mediterráneo, pp. 118-137. 


\section{APUNTES BIOGRÁFICOS}

María Manzanera Molina-Niñirola (Murcia, 1946) halla su pasión por la fotografía desde edad temprana a través del descubrimiento de un daguerrotipo en un anticuario. Este acontecimiento marca su profesión de carácter polifacética, predominando las vertientes creativa y teórica. Por un lado, desarrolla la faceta artística desde hace cuatro décadas, gozando su producción de gran heterogeneidad temática. En su etapa inicial de finales de los años setenta, recurre a retratos que reflejan un lenguaje personal y puramente fotográfico, partiendo siempre de ideas preconcebidas. En los años ochenta, la artista experimenta con el color en La atmósfera de Venus y con la de macrofotografía, revelando universos llenos texturas y matices cromáticos. En los años noventa, la autora se centra en el cuerpo humano en Captar lo Intangible, donde muestra su visión del desnudo, y en Ritmos, serie en la que capta el dinamismo del baile flamenco. En el siglo XXI, se centra en la fotografía urbana, a través de la cual muestra diversas ciudades a modo de documento social. Ejemplo de ello son las obras Manhattan, Siempre nos queda París, Murcia Verticalia o las inéditas Venecia, La Familia Humana, Museos y De Nueva York a Nuevo México. Como contrapunto, la artífice se inspira en la naturaleza en Flores Simplemente, en la que rescata el procedimiento decimonónico del emulsionado, y en La Naturaleza Inventada, para cuya concepción utiliza objetos cotidianos que se interrelacionan con el medio natural. En Jardines de Artista, rinde homenaje a los pintores Monet, Sorolla y Molina Sánchez, obteniendo creaciones de carácter preciosista e incluso de tintes pictóricos. De estética surrealista es Through, donde juega con la interposición de elementos consiguiendo resultados cercanos a la abstracción. Entre sus trabajos más recientes, se encuentran Murcia Huertana, que le sirve para reivindicar la huerta murciana y Murcia, día y noche, que viene a completar su archivo fotográfico que ha sido exhibido, desde 1981 hasta la actualidad, en numerosas exposiciones individuales y colectivas en España, Francia, Estados Unidos y Asia.

Por otro lado, destaca su faceta como investigadora desde los años ochenta. Muestra de ello son los numerosos libros que publica sobre investigaciones de fotografía y cinematografía. Su obra teórica crucial es La imagen transparente: comienzos de la fotografía en la ciudad de Murcia, 1840-1920, ya que recoge el trabajo abordado en su tesis doctoral (la primera investigación sobre fotohistoria murciana defendida en la Universidad de Murcia). Este libro es trascendental porque abarca los orígenes de la fotografía de esta ciudad, situando a Manzanera como la primera fotohistoriadora de rigor de la Región. Paralelamente, entre sus diversos estudios sobre cinematografía, destaca Cine de animación en España: Largometrajes 1945-1985, cuya relevancia radica en la puesta en valor de este arte que, hasta la década de los años noventa, no había sido objeto de estudio en el ámbito nacional.

Paralelamente, la autora ejerce labores docentes en diversos centros universitarios (Universidad de Valladolid, Universidad de Murcia, Universidad Católica San Antonio de Murcia) y educativos (Instituto Politécnico de Murcia). Asimismo, es importante su participación en actividades de fomento de la fotografía desde el Aula de Artes Plásticas y el Centro de Recursos Audiovisuales (C.R.A.V.) ${ }^{5}$ dentro de la Universidad de Murcia.

5 Desde mediados de 1980 hasta 2003, María Manzanera es la máxima responsable del Centro de Recursos Audiovisuales (C.R.A.V.), desde donde se encarga de la sección de fotografía y se dedica a documentar con sus fotografías todos los actos de la Universidad de Murcia. 
Desde dicho centro imparte seminarios, talleres y cursos en los transmite sus amplios conocimientos teórico-prácticos sobre este campo artístico. Igualmente, son significativas sus ponencias en materia fotográfica que viene realizando desde I Congreso de Historia de la Fotografía Española en 1986 hasta la actualidad.

Apasionada de la fotografía antigua, Manzanera desarrolla su labor como coleccionista desde que tiene dieciséis años. Su colección consta de numerosos ejemplares de daguerrotipos, ambrotipos, fotografías estereoscópicas y ferrotipos, datados desde la llegada de este procedimiento creativo en Murcia hasta 1920 aproximadamente. Este hecho, la situaría como la primera coleccionista seria de fotografía antigua de la Región, ya que no atiende a simples criterios acumulativos, sino investigativos.

Completando su carácter polifacético, la creativa ha llevado a cabo varios proyectos de comisariado, siendo una de las primeras mujeres fotógrafas que ejerce esta labor dentro de la Región. Destaca por su importancia Univerfoto (1987-1993), uno de los primeros festivales fotográficos de relevancia acontecido en Murcia que, además de sentar las bases para eventos de mayor envergadura, supone un gran paso para el fomento de este arte a nivel regional desde una perspectiva de acercamiento internacional.

La amplia formación de Manzanera (doctora en Historia del Arte, especialista en fotografía y en Historia y Estética de la Cinematografía), queda reflejada en su producción artística y teórica. Como reconocimiento a su trabajo, a mediados de la década de los ochenta, se le conceden becas de investigación para el Palacio Real de Madrid y para la Real Sociedad Fotográfica de Madrid, así como también se le otorgan premios nacionales en los años ochenta y noventa por su producción teórico-creativa ${ }^{6}$.

\section{FOTOGRAFÍA DE CALLE}

Siento la necesidad de captar imágenes hermosas con mi cámara, imágenes que hagan percibir, a quienes las mire, un sentimiento de bienestar semejante al mío. Me interesa, sobre todo, la figura humana, pero también aquello que, por su elegancia, componga una imagen atrayente ${ }^{7}$.

Dentro de su vertiente artística, Manzanera trabaja la fotografía de calle ${ }^{8}$, ocupando un lugar privilegiado en su archivo ya que se trata de uno de sus géneros predilectos. Habría que tener en cuenta que esta corriente es desarrollada por grandes maestros de la fotografía por los que la autora siente gran admiración: Eugène Atget, Henri Cartier-Bresson, William Eggleston, Sebastião Salgado, Eugene Smith y Alfred Stieglitz, cuya influencia se percibe en el discurso artístico de la creativa.

6 Toda la información sobre la trayectoria profesional de María Manzanera está disponible en: http:// www.mariamanzanera.es/

7 REVERTE, P. (2008): «La fotógrafa María Manzanera presenta hoy Verticalia», en La Opinión, 6 de marzo de 2008, p.67.

8 La fotografía de calle, también conocida como fotografía urbana o street photography, es definida por el crítico C. Westerbeck y el fotógrafo J. Meyerowitz como la "fotografía cándida de la vida cotidiana en espacios públicos”. En WESTERBECK, C. y MEYEROWITZ, J. (1994): Bystander: a history of street photography. Thames \& Hudson, p. 34. 
En numerosas ocasiones, la fotografía de calle está estrechamente unida al hecho de viajar. Según Vázquez Casillas, el viaje implica la aproximación a otros lugares que difieren del nuestro. Sin embargo, conviene puntualizar que ese acercamiento a la realidad es de índole subjetivo, ya que cada individuo lo experimenta de una forma íntima (Vázquez Casillas, 2008a:7). En cuanto a fotógrafos viajeros se refiere, resulta interesante la visión Jean Dieuzaide quien se deja cautivar por elementos singulares que atrapa con su cámara: «cuando se viaja a otro país, lo que más sorprende son las cosas diferentes y especiales. En ello se ha de fijar un fotógrafo, pero con respeto y buscando la autenticidad» (Dieuzaide, 1990).

En el caso de Manzanera, y en relación con la afirmación del fotógrafo francés, la autora reconoce que lo que le mueve a viajar es la unión de dos acciones: «conocer y aprender» (Manzanera, 2014a) ${ }^{9}$. Ambos términos podrían estar vinculados con el concepto de viaje entendido por Vázquez Casillas como «un componente esencial de conocimiento» (Vázquez Casillas, 2008b:7). La inquietud que la creativa siente hacia el descubrimiento de ciertos espacios, le lleva a captar con su fotografía digital y «de plata, como la llaman en Francia» (Manzanera, 2008a:) ${ }^{10}$, todos aquellos lugares que le transmiten una serie de ideas que percibe de forma particular.

La fotografía urbana permite a Manzanera expresarse a través del entorno que le rodea. Con su visión personal, se aleja de las imágenes típicas y académicas, creando representaciones espontáneas que muestran tanto elementos arquitectónicos como gente sumida en su quehacer diario. La artífice parte de la observación y busca recónditos lugares o personas que atraen su atención por la belleza que desprenden.

Para la realización de imágenes, la creadora emplea diversos recursos fotográficos, generando así un rico lenguaje estético dentro de su producción. Entre los temas más tratados, cabe destacar los paisajes tanto urbanos como rurales de determinados espacios geográficos. Estas representaciones constituyen visiones de ciudades españolas (Murcia, Madrid, Córdoba) y extranjeras (París, Londres, Manhattan, Venecia), que transmiten una profunda interrelación entre sus habitantes, la arquitectura y el mobiliario urbano. Por una parte, decide emplear el clásico binomio blanco y negro en los proyectos Manhattan, Siempre nos queda París, De Nueva York a Nuevo México, Venecia y Murcia Verticalia, una de las obras que se analiza en este estudio. Por otra parte, da rienda suelta al color en otras obras como la inédita El Sur, así como también aquellas dedicadas a la naturaleza que son Jardines de Artista y Murcia Huertana, libro que se examina como una apología a la flora y al medio natural murciano. Igualmente, su trabajo más reciente, Murcia, día y noche, se analiza en el artículo revelando una ciudad viva y cambiante a merced de la luz.

9 MANZANERA. M., comunicación personal, 31 de marzo de 2014.

10 María Manzanera define de esta forma la fotografía analógica en: GUARDIOLA, A. (2008): «Murcia, de la tierra al cielo», en La Opinión, 9 de marzo de 2008, p. 48. 


\subsection{Murcia Verticalia}

Es una especie de prueba, como una obligación de adivinar lo que se está viendo ${ }^{11}$.

El trabajo Murcia Verticalia, recibe su nombre debido al formato vertical que adoptan las imágenes que lo conforman. Publicado en marzo de 2008, se presenta con una breve introducción de la autora, precediendo al prólogo de José Fernando Vázquez Casillas titulado "Cuando el fotógrafo mira por nosotros todo nos parece distinto". En el texto, el historiador del arte reflexiona sobre la capacidad que tiene la fotografía de sublimar la realidad y sobre la necesidad expresiva que siente un fotógrafo de plasmar su visión personal.

El proyecto consta de ochenta y dos escenografías de una Murcia llena de contrastes, donde conviven el pasado y el presente dentro de la misma fisionomía urbana. A lo largo de esta narración iniciada en 2004, aparece una gran variedad de elementos de carácter arquitectónico, paisajístico y sobre todo, humano. Todo pasa por el filtro creativo de la artífice, creando miradas sesgadas que invitan a imaginar cómo se desarrollarían en su conjunto, ya que según Manzanera, «una plaza por la que alguna vez hemos transitado es fácilmente reconocible al verla fotografiada; pero, un trozo, un rincón, un portal... Nos despista muchísimo» (Manzanera, 2008b:64).

Esta serie es planteada como un paseo visual de encuadres equilibrados en los que se reflejan las transformaciones que ha sufrido su ciudad natal. Las representaciones son protagonizadas por edificaciones como el cuartel de Artillería, la fábrica de seda Piamontessa, el edificio de la Unión y el Fénix y la emblemática plaza de toros. Aparecen multitud de casas entre las que se encuentran la Casa Blanca, Díaz Casou y el palacio de Almodóvar. Calles como la del Escultor Salzillo, Alejandro Séiquer y el Arenal inundan las imágenes. Entre las plazas con las que cuenta están la de Belluga, de las Flores, Santo Domingo, San Bartolomé, Santa Catalina, Santa Isabel, Europa y de la Fuensanta. La fotógrafa dedica su objetivo a jardines tales como el Botánico, de la Pólvora, de Fofó y de la Seda; a pórticos como el del Malecón; al mercado de Verónicas y a puentes como el de los Peligros. Los museos de Bellas Artes, Ramón Gaya y de Artesanía quedan representados en la misma serie. Monumentos a Salzillo y al Colorao no faltan en el libro, así como tampoco arcos como el de San Juan. Igualmente, iglesias como la de San Nicolás y conventos como el de Santa Clara la Real completan la estampa murciana.

Estos espacios son inundados de habitantes anónimos aunque en ocasiones, aparecen figuras excepcionales como la de Francisco Rabal a modo de homenaje escultórico. En estos escenarios aparece el hombre, explícita o implícitamente, como autor de los cambios y del devenir de lo urbano. De esta manera, Manzanera presenta al ser humano como el responsable de las alteraciones que han acontecido progresivamente en la urbe. Si bien es cierto que las imágenes resultan familiares, podrían pertenecer a cualquier lugar del mundo, ya que la artífice aborda los temas con una percepción global, captando el alma del lugar. Ejemplos de ello son las series Manhattan, Siempre nos queda París y De Nueva York a Nuevo México.

11 SOLER GÓMEZ, P. (2008): "Murcia Verticalia: muestra las imágenes de la ciudad vista pero desconocida", en La Verdad, 6 de marzo de 2008, p. 64. 
Completando este ejercicio gráfico, se añaden textos de personalidades relacionadas con el mundo de la cultura. Destacan las aportaciones de Frutos Baeza, Alemán Sáinz, García Abellán, Gaya, González Vidal, García Martínez, Sánchez Bautista y Sánchez Rosillo, entre otros. En cuyos escritos, aparecen diversas referencias a tradiciones, gentes y ambientes de Murcia, enriqueciendo y complementando acertadamente las fotografías.

\section{Imagen 1 \\ MARÍA MANZANERA. LA CASA BLANCA. \\ CALLE SAAVEDRA FAJARDO. H. 2005}

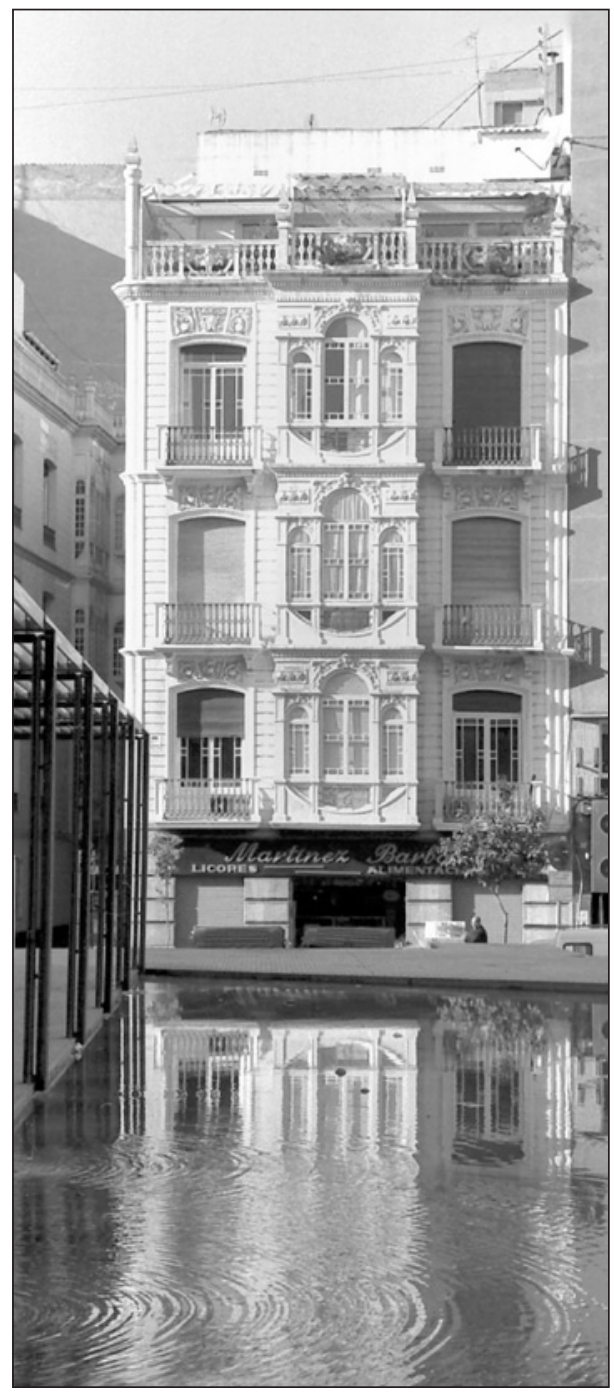

Cuadernos de Turismo, 42, (2018), 71-91 
A la hora de concebir Murcia Verticalia, la creadora reflexiona sobre la posibilidad de plantear la ciudad en disposición vertical, recurso empleado en sus anteriores series dedicadas a París y Nueva York. Para Manzanera, las imágenes verticales son «tan elegantes» (Manzanera, 2008c:64) que se plantea el proyecto «como un reto, porque se trataba de captar verticalidad donde prácticamente o apenas no existe» (Manzanera, 2008d:64). Para este trabajo, la artífice recurre a su característico lenguaje fotográfico puro y sin artificios, que le sirve para presentar una ciudad que conoce muy bien, ya que la mayoría de los lugares se asocian a la autora de cierta manera. La creativa atrapa todo aquello que le llama la atención visual y anímicamente, utilizando el discurso en blanco y negro, hecho que puede llegar a despistar al espectador. En este aspecto, afirma la fotógrafa que, tanto el formato vertical como el clásico binomio, juegan un papel decisivo en esta serie:

Esto hace que el espectador se centre un poco, por lo que puede parecer irreal lo que está viendo. Es que casi siempre he hecho mis fotografías en blanco y negro porque tienen algo especial para mí, quizá que no son la realidad, sino una variación (Manzanera, 2008e:65).

Las fotografías se presentan como fragmentos que plantean un juego visual que incite al espectador a identificar lugar representado. Según la propia autora, pretende «mostrar tranquilidad en un momento en el que la vida está llena de cosas que alteran» (Manzanera, 2008f: 65). Al respecto, Vázquez Casillas señala que con estas obras se invita «a reconocer lo conocido» (Vázquez Casillas, 2007a:12), de ahí que la información de la imagen aparezca en su correspondiente reverso. Partiendo de esta premisa, no sólo se propone la obra como una estimulación sensorial, sino también como un trabajo de memoria que invita a la observación y reflexión del entorno:

Pensé que las fotos podrían ser un aliciente, porque yo pasaba por ciertos sitios que he estado contemplando toda la vida, pero sin que jamás me hubiese dado cuenta de que en esa calle o en esa plaza existía un determinado detalle que fuese interesante y atractivo. Hacer estas fotografías era para mí, pero seguro que también para quien pueda contemplarlas en el libro, como un ejercicio de captación de lo desconocido (Manzanera, 2008g: 64).

Como se menciona previamente, Murcia ya había sido fotografiada en numerosas ocasiones, captándola a modo de tarjeta postal o dentro del reportaje gráfico en el ámbito de la prensa. Hasta la publicación de este libro, la ciudad no había sido retratada bajo los principios de verticalidad a los que la autora la somete. Con ello, se pone en valor el carácter pionero de Murcia Verticalia, aunando imagen y palabra para transmitir, según Vázquez Casillas, un sentimiento quizá de «lamento entendido éste como añoranza» (Vázquez Casillas, 2007b:12). En este trabajo, Manzanera muestra a su ciudad natal como un espacio que ya no identifica completamente, sólo algunos lugares o elementos de ésta, pretexto que invita al lector a descubrirla e incluso a redescubrirla. Se trata de un recorrido compuesto por visiones urbanas que transmiten la esencia de una ciudad en constante transformación, visible a través de una selección de meditados encuadres que revelan una notable sensibilidad artística. 


\section{Imagen 2 \\ MARÍA MANZANERA. JARDÍN DE LA PÓLVORA. H. 2005.}

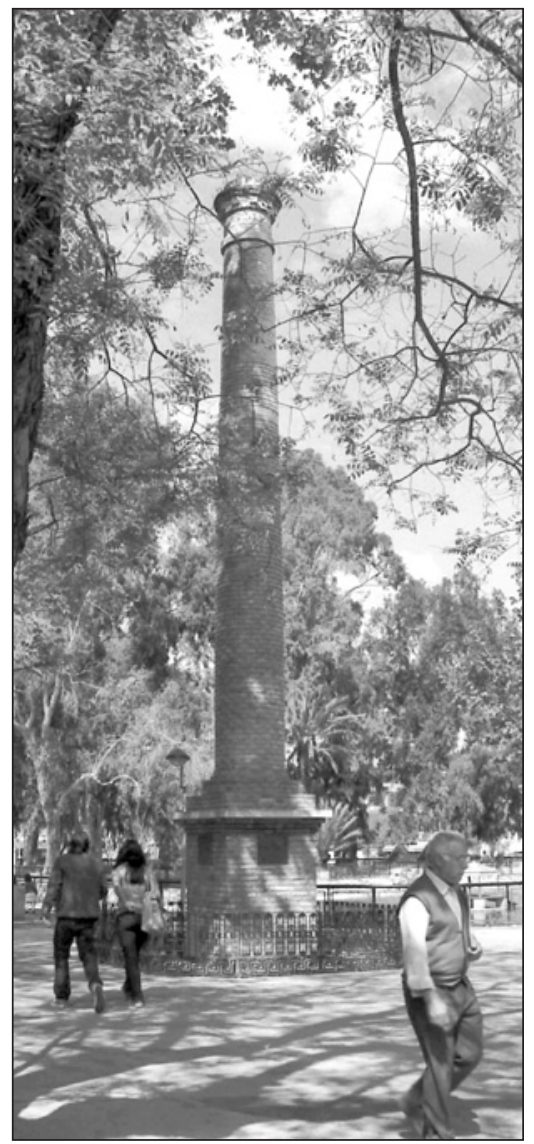

\subsection{Murcia Huertana}

Si nosotros tenemos algo especial, como es la huerta, -que no está en otro sitio de Europa-, eso es lo que habría que mimar, conservar y apoyar ${ }^{12}$.

El primer trabajo fotográfico de Manzanera dedicado a la huerta, se publica en diciembre de 2014 y recibe el título de Murcia Huertana. La obra presenta un recorrido por el paisaje natural murciano, compuesto de acequias, fauna y flora, teniendo como finalidad ayudar a conocer la huerta de Murcia. A modo de prólogo, el crítico literario José Belmonte concibe la huerta como "Restos de un naufragio", texto en el que enaltece este proyecto que logra perpetuar en la memoria la huerta con belleza y respeto.

12 MANZANERA. M., comunicación personal, 31 de marzo de 2014. 
Con una ilustración de José Antonio Molina Sánchez como portada, el libro consta de ochenta fotografías inundadas de vida e intensa luz mediterránea. La fotógrafa inmortaliza con su objetivo la gran riqueza que caracteriza la huerta murciana a través del río Segura y una selección de especies florales (calas, borrajas). Representa plantas de varios tipos como las herbáceas (patatas, habas, tomates, perejiles, vinagrillos), vitáceas (parras), gramíneas (carrizos, panizos, cálamos), hortenses (acelgas), compuestas (cardos), arbóreas (palmeras) y arbustos (zarzas). En cuanto a árboles, retrata frutales (naranjos, limoneros, nísperos, granados, almendros, perales), abietáceos (pinos), ulmáceos (olmos) y de origen exótico como el cinamomo. Ante tal diversidad, la artífice exclama: «ipero qué variedad de plantas tan bonitas, tan desconocidas! Pero la gente no las conoce, aunque seamos de Murcia» (Manzanera, 2014b).

Igualmente, la fauna es protagonista de sus imágenes (gallos, vacas, caballos), así como también lo son construcciones que conforman el paisaje huertano: el azud de la Contraparada, la red de acequias, norias y puentes. Asimismo, aparecen hornos de adobe y ladrillo, molinos hidráulicos -para moler trigo y pólvora-, ermitas y casas-torre. De esta forma, quedan representados elementos que recuerdan la presencia musulmana en esta ciudad. Todo ello se completa con fotografías de tinajas de agua, instantáneas del juego de bolos huertanos y alusiones a la indumentaria regional de Murcia a través del moño de picaporte, imagen destinada a coronar la contraportada del libro.

Las imágenes reflejan aspectos de la naturaleza que han logrado sobrevivir al paso del tiempo y a la destructiva mano del hombre que sigue minando la histórica huerta. Para la autora, todos estos elementos fotografiados desprenden «una hermosura que existe, que es real, actual y auténtica» tratándose de «nuestra fuerza y nuestro hálito vital» (Manzanera, 2014c:4). De este modo, con esta obra pretende concienciar al espectador de la presencia de la huerta, su riqueza y variedad aún desconocidas por muchos de nosotros.

El trabajo es concebido en 2008, momento desde el cual la artista afirma que comienza « a recorrer la huerta, a entrar por los carriles y las sendas» de modo que se fue «entusiasmando con lo que veía» (Manzanera, 2014d). Con la intención de mostrar la belleza que esconde y despertar el interés por lo que nos identifica, la autora capta la esencia de la huerta con el fin de conservarla: «porque si no conservamos lo que es nuestro, no somos nadie» (Manzanera, 2014e). Ante la necesidad de preservar un pasado histórico que nos define, la creativa capta con su ingenio y con su cámara aquellos rincones dignos de consideración y respeto, aclamando el urgente y necesario apoyo que debe prestarse al asunto: «porque, ¿quién está apoyando a la huerta? ¿Quién está creando y ha creado la huerta? ¡Los huertanos! Entonces, a esas personas son a las que hay que ayudar» (Manzanera, 2014f).

Es destacable que el vínculo estrecho que la fotógrafa tiene con la huerta, puesto que tiene familiares huertanos tal y como afirma: «mi padre me llevaba con seis o siete años a casa de mi tío Mariano. Él era agricultor, trabajaba la tierra y tenía vacas y una sala con gusanos de seda» (Manzanera, 2014g). Por tanto, desde su infancia se familiariza con las labores de la agricultura, la ganadería y con los paisajes rurales, surgiendo en su interior el impulso de luchar por dicho patrimonio natural. Con las siguientes palabras, la creativa manifiesta que el amor que siente tanto por la fotografía como por la huerta: 
Hace varios años comencé a tomar fotografías de la huerta porque mi vocación es tomar fotografías de la belleza donde exista, y porque la huerta tira de mí con una fuerza especial quizá porque mis abuelos paterno y materno, fueron huertanos (Manzanera, 2014h: 4) ${ }^{13}$.

\section{Imagen 3}

MARÍA MANZANERA. CAMINO RUEDA DE LA ÑORA. H. 2010.

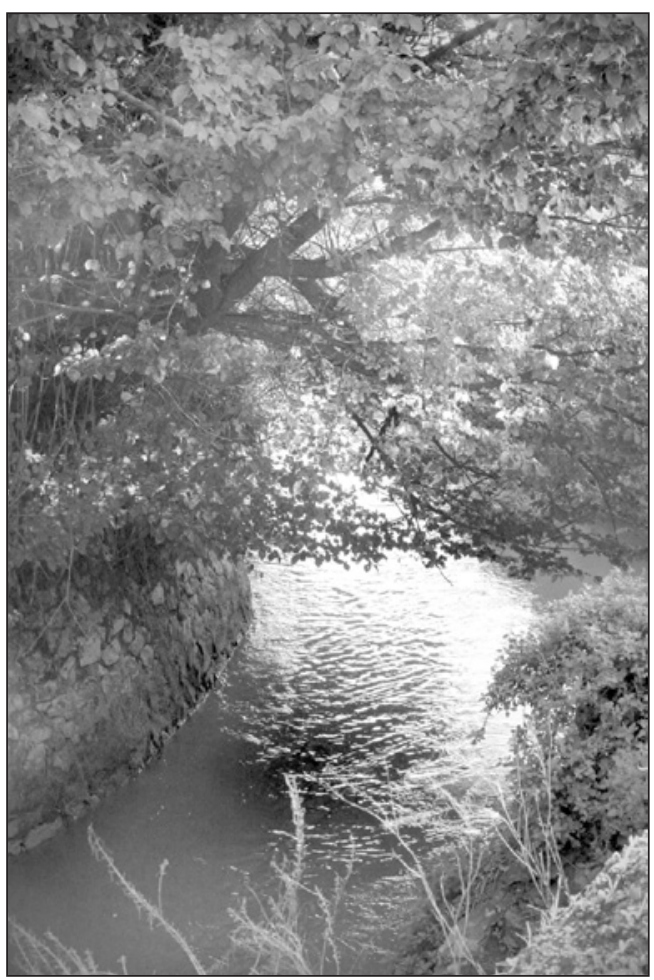

En el libro se incluyen escritos en español e inglés, por lo que la artífice no sólo dedica su mirada a estos escenarios que le cautivan, sino que también ofrece poéticos y documentados textos que transmiten cierta tristeza melancólica. En sus afirmaciones, advertimos «una idea en la que la nostalgia pesaría menos que la urgencia» (Manzanera, 2014i). Se trata de aclaraciones sobre diversos aspectos de la huerta como el sistema de regadío mediante acequias y azarbes, determinadas especies vegetales endémicas o comentarios con anotaciones de interés histórico y son esenciales para conocer la huerta murciana. Los escritos, resultan acertados ya que según José Belmonte, vienen a completar las fotografías que «despiertan irremediablemente la imaginación» (Belmonte, 2014a:12).

En cuanto a recursos empleados se refiere, la fotógrafa recupera el color como medio indispensable para mostrar el esplendor y la riqueza cromática de la huerta de Murcia.

13 MANZANERA. M., comunicación personal, 19 de agosto de 2014. 
Acorde con su lenguaje personal, y según afirma Belmonte, se trata de una selección de fotografías «de hermosísima factura, limpias y claras como un cielo septembrino, sin caer en la tentación del siempre contagioso y manido barroquismo murciano» (Belmonte, 2014b:10). Como resultado, se obtienen obras de composición cuidada y delicados encuadres que reflejan los signos que identifican la huerta.

Ante el evidente desinterés por conservar esta tierra fértil, Manzanera lucha por hacerla visible para concienciar sobre su preservación. Se trata de una lucha cargada de esperanza y optimismo, ya que las fotografías dan fe testimonial de la huerta murciana aún presente. Teniendo en cuenta la idea con la que la autora concibe el proyecto, se puede afirmar que este ejercicio fotográfico encierra «una protesta contenida» (Manzanera, 2014j) ante «una cultura perdida y que se está escapando entre los dedos» (Manzanera, 2014k).

Ante esta marcha forzada de pérdida de la identidad y para combatir el olvido de la huerta de Murcia, la artífice emplea su ingenio artístico y acerca al espectador a bellos rincones «para que sepan que están ahí» (Manzanera, 2014l). Éstos todavía conservan su estado primigenio, su verdadera naturaleza, por lo que siendo o no una batalla perdida, María Manzanera realiza una crítica implícita con el fin de preservar la tierra que siempre la ha identificado, haciéndolo con su arma más poderosa, la fotografía.

\section{Imagen 4 \\ MARÍA MANZANERA. ALGEZARES. CARRIL DE LOS SERNA. H. 2010.}

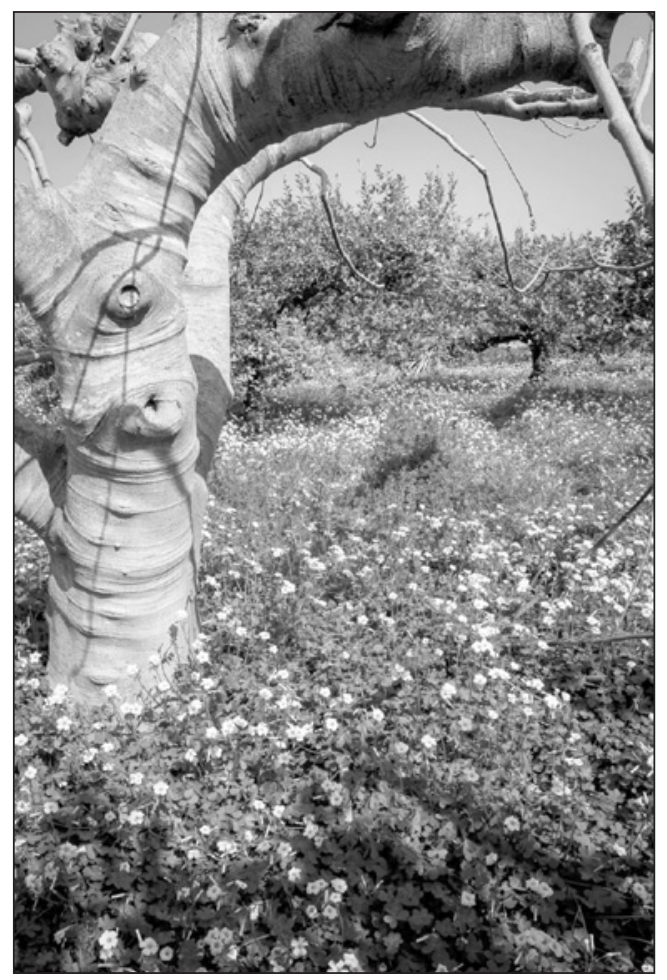




\subsection{Murcia, día y noche}

Este libro nos sirve de guía para conocer mejor nuestra ciudad, que acostumbramos a recorrer sin reparar en los elementos importantes que hay en ella ${ }^{14}$.

El último trabajo de Manzanera titulado Murcia, día y noche, constituye el tercer proyecto dedicado a su ciudad natal. Publicado en abril de 2017, cuenta con un prólogo de Antonio Botías que recibe el título de "En busca de la realidad perdida". En éste, revisa brevemente las aportaciones de una selección de fotógrafos que retratan Murcia desde el origen de la fotografía, sirviendo de pretexto para introducir la obra de Manzanera. El escritor, pone en valor el trabajo teórico-creativo de la autora a nivel general, destacando «el don de hallar en cada lugar aquello que el resto de los mortales intuye, saborea e incluso huele, pero que no es capaz de fijar sobre la memoria, cuando menos en el papel» (Botías, 2017b:6).

El libro cuenta con ilustraciones de José Antonio Molina Sánchez en la portada, al igual que en la obra Murcia Huertana, por lo que de nuevo la creativa rinde homenaje al pintor con el que guarda relación de parentesco. El trabajo consta de un total de noventa y una fotografías, de las cuales la mitad son captadas de día y las restantes son realizadas de noche. Las imágenes reflejan la esencia urbana de Murcia a través de su gente y arquitectura. Por ello, no faltan monumentos como la catedral de Santa María, el Real Casino y los emblemáticos Palacio Episcopal y Teatro Romea. Completando la estampa, se suceden multitud de palacios con sus fachadas y sus interiores jalonados de obras de arte y majestuosas escaleras. También las iglesias atraen el interés la fotógrafa, ya que sus fachadas «son muy especiales para detenernos, porque ahí en esos relieves que hay detalles muy curiosos» (Manzanera, 2017c) ${ }^{15}$. Del mismo modo, las calles son las protagonistas de esta serie, siendo concebidas como espacios transitados por paseantes que no suelen percatarse de los elementos que las conforman. Tampoco faltan alusiones al Río Segura, sus puentes y sus características flora y fauna que atrae a pescadores y curiosos. La mirada fotográfica de Manzanera se detiene ante las fuentes de la ciudad, plazas, arcos, antiguos barrios, mercados, conventos e, incluso, en establecimientos de diversa índole como cines, tascas y ferreterías.

Todas las fotografías van acompañadas de textos en edición bilingüe. Dicha selección aporta información sobre la autoría y época de construcción de los edificios, añadiéndose el nombre de la calle y el número donde se ubica la imagen. Igualmente, la autora proporciona datos históricos sobre plazas, barrios, monumentos y arcos, por lo que sus aclaraciones fomentan el interés por conocer en profundidad a Murcia. Tal y como apunta la autora «los textos referentes a cada fotografía van detrás de ella» (Manzanera, 2017d) ${ }^{16}$, de esa manera, al visualizar primero la imagen, obliga al lector a recordar qué conocimientos se tiene acerca de ese espacio representado, para posteriormente, corroborar y/o completar esa información proporcionada. Al respecto, Botías apunta que «recorrer las páginas del libro es recorrer Murcia» logrando «mantener el pulso de la curiosidad que plantea la autora para el descubrimiento del detalle» (Botías, 2017c:6).

14 MANZANERA, M. (2017): Murcia, día y noche: fotografías. Murcia, Fundación Cajamurcia, Pictografía, p. 10.

15 MANZANERA. M. (5 de abril de 2017). Entrevista por Carmen Campos. Onda Regional de Murcia.

16 MANZANERA. M. Comunicación personal, 21 de abril de 2017. 
La serie Murcia, día y noche es concebida en 2015 y según Manzanera, surge «como una idea dormida que llevas dentro y por alguna razón, en un momento dado, sale a flote» (Manzanera, 2017e $)^{17}$. La artista plantea «un ejercicio de memoria visual» (Manzanera, 2017:0) con el fin de conocer mejor Murcia, ya que ella percibe «falta interés por decir qué casa tan bonita, qué plaza tan bien trazada, quién haría esto... Es algo que no nos preguntamos y deberíamos de hacerlo». (Manzanera, 2017f). Ante esa escasa curiosidad, la creativa ofrece su visión particular utilizando la fotografía como medio de acercamiento. Manzanera define esta obra como «un recorrido pormenorizado por la ciudad de Murcia para recordar o aprender calles, plazas o detalles que nos pasan inadvertidos» (Manzanera, 2017g) ${ }^{18}$, transmitiendo los conocimientos que ha adquirido para la realización del proyecto.

\section{Imagen $\mathbf{5}$ \\ MARÍA MANZANERA. SOCIEDAD DE CAZADORES. H. 2015.}

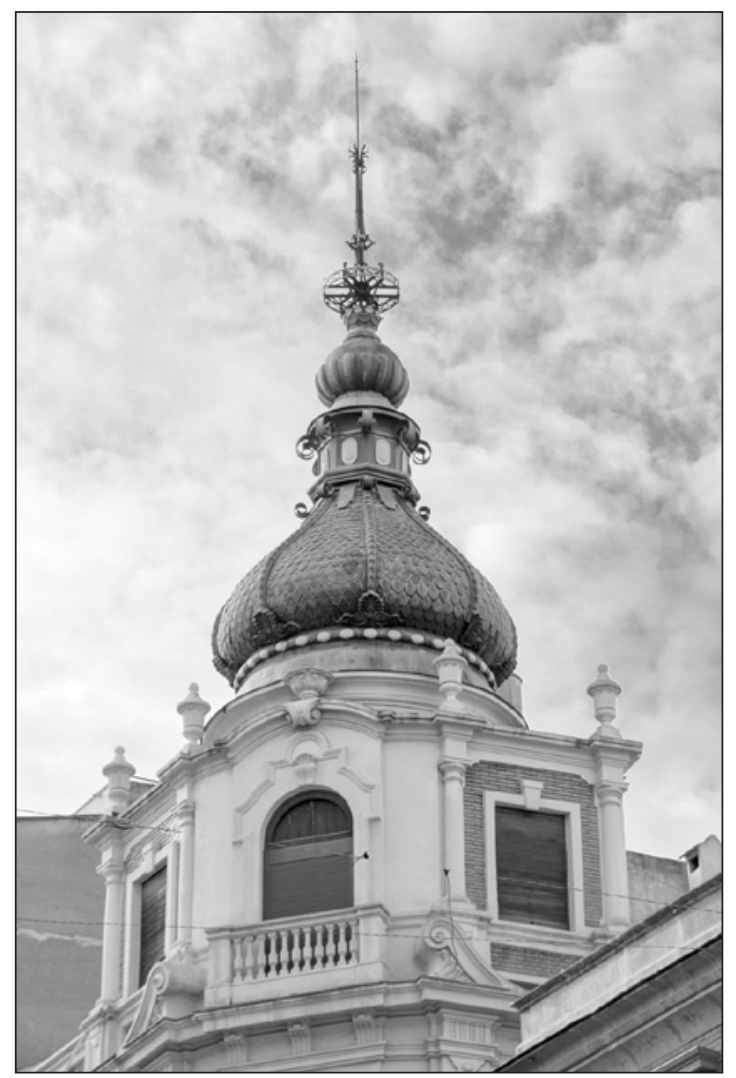

17 Ibídem.

18 MANZANERA, M. (2017): Murcia, día y noche: fotografías. Ob. Cit., p. 1. 
El libro se estructura en dos partes bien diferenciadas: en la primera, capta la esencia diurna de Murcia, mientras que en la segunda desvela la transformación que tiene al caer el sol. Para Manzanera resulta de especial interés la última parte debido al misterio que encierra la ciudad de noche:

Podríamos decir que otra ciudad surge de noche. La vida nocturna brota y algunos rincones ignorados cobran vida. Los conciertos dejan oír su armonía y los teatros sus voces. También hay veces que la ciudad permanece callada y serena, aguardando ese misterio que nunca viene con el día» (Manzanera, 2017h:107).

Estas palabras sirven de preludio a la colección de imágenes de una Murcia carente de luz solar. Se trata de una perspectiva atrayente e insólita de la ciudad, donde se percibe un aire enigmático que aguarda en la oscuridad. Hasta este trabajo, la nocturnidad murciana no es retratada ni publicada monográficamente, por lo que podría considerarse a Manzanera como la primera fotógrafa que presenta un libro que refleja la ciudad de noche, completando así el archivo visual de ésta.

Para la consecución de este trabajo, emplea los recursos fotográficos que caracterizan su discurso artístico: lenguaje puro, sin artificios ni manipulaciones, iluminación estudiada, composiciones delicadas, color cuidado, formato vertical y encuadres impecables. Según Botías, la artífice hace uso de «una técnica fabulosa, un gran conocimiento de la ciudad y destacadas dosis de arte» (Botías, 2017d:6). Entre los elementos externos a los que recurre Manzanera está el agua, bien fluyendo por el río, bien sirviendo de espejo en cuyo reflejo se vislumbran edificios como la torre de la catedral. La artista, juega con este agente que le permite crear efectos esplendentes, pues «es como tener algo que está en el aire, pero que de pronto lo vemos ahí al lado de nuestros pies, y además, con toda la viveza, con todo el colorido» (Manzanera, 2017i).

Si bien es cierto que en la serie Murcia Verticalia utiliza la misma disposición vertical, en Murcia, día y noche no hay una finalidad determinante, sino que aporta un enfoque fresco y más identificativo, recupera el color y se aleja del carácter global. En este sentido, el propio Botías aclama este trabajo valorando sus aportaciones:

Este libro, como ya hiciera en los anteriores, en todos los casos aclamados por el público y ensalzados por los académicos, nos ofrece una visión distinta y vibrante de nuestra amada Murcia, una ciudad que se enciende en fachadas tostadas de sol, como cantara el poeta Jorge Guillén, para oscurecerse bajo el a increíble luz de la luna que, a unos cuantos cientos de metros se recorta todavía entre las últimas palmeras de la huerta (Botías, 2017e:6).

La obra constituye una invitación explícita a la experimentación, la fotógrafa incita a sentir y a comprender Murcia, pues tal y como incita Manzanera «conozcamos cuáles son sus edificios más notables, sus autores, la época en que se construyeron...Conozcamos un poco mejor la ciudad donde vivimos o visitamos temporalmente» (Manzanera, 2017j $)^{19}$. En estrecha relación con su pasión por la docencia, según Botías, la creativa nos deleita con su genio creativo y la transmisión de sus conocimientos con la

19 Ibídem. 
intención de «enseñar a Murcia con una visión distinta, actual, emocionante y bella» (Botías, 2017f:8). Pues no sólo se dedica a retratar la ciudad, sino que hace una labor de investigación sobre edificios y rincones que le llaman la atención. De ese modo, se le permite ofrecer tal valiosa información a todas las personas interesadas en conocer este histórico lugar.

A través de Murcia, día y noche, Manzanera revela múltiples puntos de vista, recordando espacios que la hacen única y descubriendo elementos que pasan desapercibidos. Como resultado, obtiene imágenes de una ciudad viva tanto con la luz cálida y diurna como con la misteriosa luz nocturna. De esta forma, contribuye con su arte a difundir y redescubrir el encanto que Murcia encierra.

\section{CONCLUSIONES}

A diferencia de las representaciones gráficas de Murcia desde mediados del siglo XIX hasta nuestros días, Manzanera retrata la ciudad desde un punto de vista diferente. La artista huye de las demandadas panorámicas y vistas académicas de monumentos murcianos, ya que su objetivo es adentrarse en su historia, calles y rincones que suelen ser ignorados por los viandantes. Se trata de un acercamiento al entorno con la intención de captar la belleza que subyace en las escenas que contempla. Para ello, emplea recursos puramente fotográficos, un lenguaje personal y directo que combina, indistintamente, el blanco y negro o el color en fotografías que reflejan una perspectiva inusual de la urbe. Ejemplos de ello son sus trabajos Murcia Verticalia, Murcia Huertana y Murcia, día y noche, donde a través de la mirada fotográfica de la autora, se muestra una ciudad casi desconocida.

Murcia Verticalia (2007), constituye el primer proyecto de Manzanera sobre su ciudad natal. Se concibe con el fin de subsanar el desconocimiento que la autora percibe que tiene este lugar. Para su consecución, plantea un juego de adivinanzas visuales que invitan a descubrir Murcia a través de determinados espacios, edificios y monumentos que tienen vinculación con la creativa. Todos estos elementos son sometidos a criterios de verticalidad, ofreciendo una visión novedosa de la ciudad que, hasta entonces, no había sido presentada monográficamente en ese formato. Bajo su característico lenguaje en blanco y negro y su filtro creativo, la autora obtiene imágenes que se conciben como «un recorrido íntimo en el que, como en todos sus trabajos, nos deja su experiencia vital de forma subjetiva, reflejándose a sí misma en cada una de las composiciones» (Vázquez Casillas, 2007c:12).

Murcia Huertana (2014), el segundo libro que dedica a la capital, se presenta como un homenaje a la huerta. Como contrapunto a la visión urbana de Murcia Verticalia, Manzanera recoge en las fotografías la luz cálida y mediterránea que baña este paraíso terrenal. Se trata de un trabajo que muestra la huerta tal cuál es, de forma directa, pero seleccionando idílicos rincones y atrapando la esencia que desprende. En esta apología subyace una protesta contenida en la que no falta la representación de la flora endémica ni la fauna autóctona, así como tampoco acequias, norias y puentes que conforman la tierra murciana. La obra supone un deleite sensorial generado, por un lado, por la sinfonía cromática de «la huerta de Europa» (Manzanera, 201411) desde tiempos romanos; 
y por otro, por la gran variedad de especies vegetales que la identifican. Los textos que acompañan las imágenes, documentan sobre el valor e importancia de este terreno fértil; mientras que las fotografías son un testimonio gráfico de la huerta, patrimonio por el que la artista insta a que se luche para su preservación.

\section{Imagen 6 \\ MARÍA MANZANERA. NOCHE OSCURA. H. 2015.}

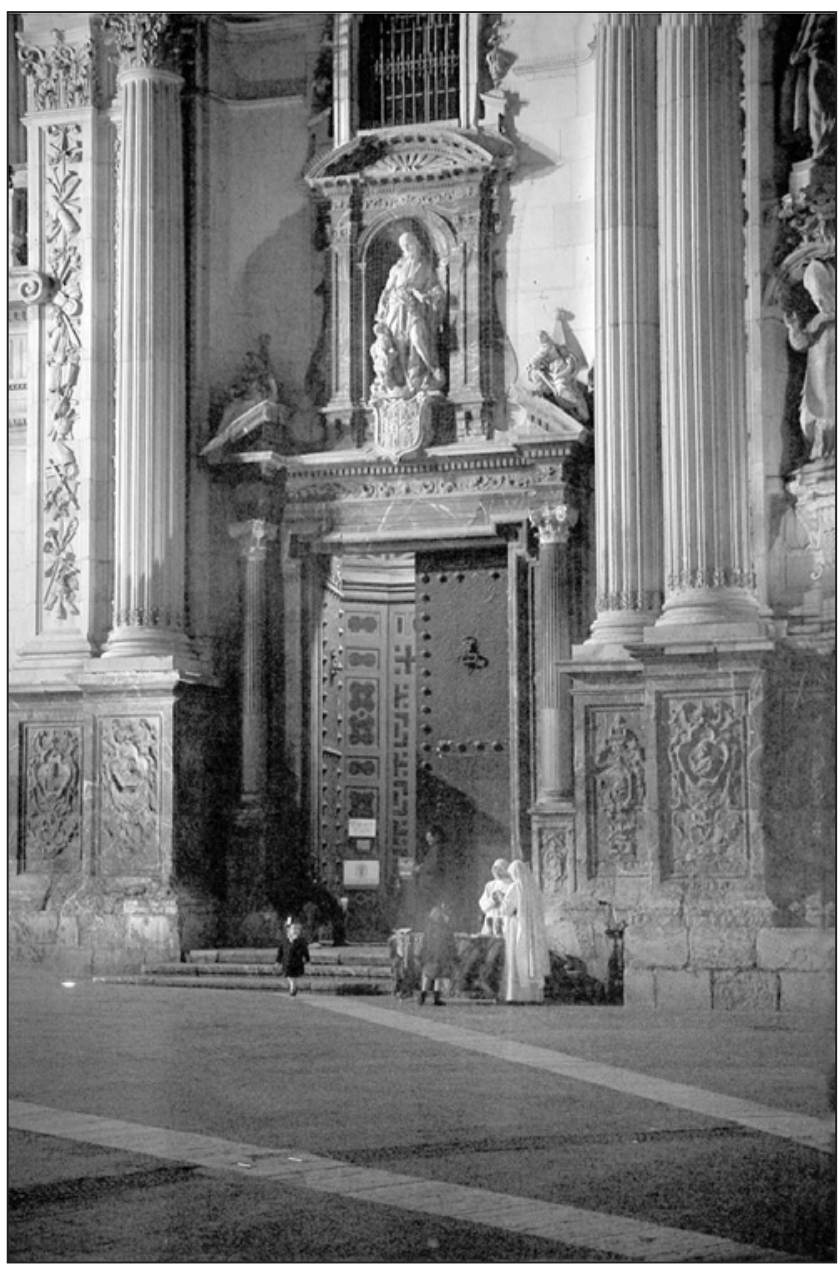

Murcia, día y noche (2017), el proyecto más reciente de Manzanera, plantea un recorrido por sus calles y edificios más representativos. Mediante ese paseo visual, emergen dos visiones diferentes de una misma ciudad: una que se yergue majestuosa bajo los tórridos rayos de sol; mientras que otra misteriosa se deja vislumbrar bajo la luz de la luna. En la serie, la artífice presenta una dualidad de Murcia como si de dos caras de 
una moneda se tratase, generando representaciones contrastadas. A diferencia de Murcia Verticalia que se compone de visiones diurnas en blanco y negro, en este trabajo recupera el color y ofrece imágenes identificativas y reconocibles. Bajo su prisma creativo, la autora revela una ciudad compuesta de elementos que, en ocasiones, son desapercibidos. De este modo, Manzanera invita al espectador a (re)descubrir Murcia, tanto de día como de noche, a través de una selección de fotografías que muestran la ciudad de una forma diferente antes entonces representada. En estas series, el espacio es sometido a un proceso de acercamiento como medio de conocimiento. Por ello, a través de la observación y de la entrenada mirada artística de Manzanera, se conecta el resorte motivacional: conocer y dar a conocer Murcia. Con su cámara, sublima aquello que le transmite sensación de bienestar, creando imágenes que constituyen una visión identificativa que trasciende los límites geográficos:

En la era de la imagen y el culto a la inmediatez, su obra ha logrado encontrar, por la evidente maestría, elegancia y oportunidad que la iluminan, un destacado hueco ya no solo en la sociedad murciana sino en otras latitudes (Botías, 2017g: 6).

En definitiva, Murcia Verticalia, Murcia Huertana y Murcia, día y noche, son trabajos que retratan Murcia desde una perspectiva personal. La ciudad es representada bajo múltiples puntos de vista: formato vertical o apaisado; blanco y negro o color; de día o de noche; y ámbito urbano o rural. Sin embargo, la fotógrafa capta a modo de documento la esencia que la identifica a través de imágenes directas de gran plasticidad, enlazando con la fotografía de calle. Adentrémonos, pues, en los recorridos visuales que plantea María Manzanera y dejémonos sorprender por sus fotografías que revelan esta urbe centenaria.

\section{BIBLIOGRAFÍA}

A.A.V.V. (2003): Fotografía en la Región de Murcia. Murcia, Dirección de Proyectos e Iniciativas Culturales, Centro Histórico Fotográfico Región de Murcia, Caja de Ahorros del Mediterráneo.

A.A.V.V. (1988): Univerfoto 1988, Murcia, Universidad de Murcia, Vicerrectorado de Extensión Universitaria, Servicio de Actividades Culturales, Aula de Artes Plásticas.

A.A.V.V. (1991): Univerfoto 1991, Murcia, Universidad de Murcia, Vicerrectorado de Cultura, Centro de Recursos Audiovisuales (C.R.A.V.).

A.A.V.V. (1992): Univerfoto 1992, Murcia, Universidad de Murcia, Vicerrectorado de Cultura, Centro de Recursos Audiovisuales (C.R.A.V.).

A.A.V.V. (1993): Univerfoto 1993, Murcia, Universidad de Murcia, Vicerrectorado de Cultura, Centro de Recursos Audiovisuales (C.R.A.V.)

A.A.V.V. (2010): Viajeros y fotógrafos de la Historia de Murcia. Taller de Historia del Archivo General. Murcia, Ediciones Tres Fronteras, Consejería de Cultura y Turismo.

CÁRCELES, M. J. (2008): «María Manzanera, fotógrafa de plata», en Artloft, $\mathrm{n}^{\circ} 07$, marzo de 2007. Murcia: Monreal \& Artloft, pp. 8-9. 
DÍAZ BURGOS, J. M. y ROIG MECA, A. J. (2004): Tarjeta postal: Región de Murcia (exposición). Murcia, Centro Histórico Fotográfico de la Región de Murcia (CEHIFORM).

DIEUZAIDE, J. (2008): Jean Dieuzaide. Fotografías de la región de Murcia, 1951. Murcia, Ediciones Tres Fronteras, Foto-grafía. Miradas.

GUARDIOLA, A. (2008): «Murcia, de la tierra al cielo», en La Opinión, 9 de marzo de 2008.

IMBERNÓN, C. y MANZANERA, M. (1987): Murcia: primer cuarto de siglo, Murcia, Universidad de Murcia, Secretaría de Publicaciones e Intercambio Científico.

MANZANERA, M. (1993): Hace 100 años: imágenes de nuestra región y la obra murciana de Guirao Girada. Murcia, Fundación Cultural CAM.

MANZANERA, M. (1997a): «Hacia una historia fotográfica de Murcia: desde sus inicios hasta 1930», en PÁEZ, M. y HERNÁNDEZ, C. (1997): Contraparada 18: Murcia, 1902-1936, una época dorada de las artes, Arte en Murcia, Murcia, pp. 52-55.

MANZANERA, M. (1997b): Murcia entre dos siglos. Tomo II. Elche, Rafael Amorós.

MANZANERA, M. (1999): La obra de Guirao Girada. Madrid, Caja de Madrid.

MANZANERA, M. (2002): La Imagen Transparente: Comienzos de la fotografía en la ciudad de Murcia, 1840-1920. Murcia, Cajamurcia, Fotoencuentros.

MANZANERA, M. (2003): Nuestro pasado fotográfico: Murcia memorable. Tomo I. Murcia, Diego Marín.

MANZANERA, M. (2004). Nuestro pasado fotográfico: Cartagena inolvidable. Tomo II. Murcia, Diego Marín.

MANZANERA, M. (2006): Nuestro pasado fotográfico: Huerta y ciudad, la Murcia de Guirao Girada. Tomo III. Murcia, Diego Marín.

MANZANERA, M. (2007): Murcia Verticalia. Murcia, Diego Marín.

MANZANERA, M. (2012): Siempre nos queda París. Murcia, Pictografía.

MANZANERA, M. (2014): Murcia huertana. Murcia, Fundación Cajamurcia.

MANZANERA, M. (2017): Murcia, día y noche: fotografías. Murcia, Fundación Cajamurcia, Pictografía.

REVERTE, P. (2008): «La fotógrafa María Manzanera presenta hoy Verticalia», en La Opinión, 6 de marzo de 2008.

SCOTT, C. (2007): Street photography: from Atget to Cartier Bresson. I. B. Tauris.

SOLER GÓMEZ, P. (2008): "Murcia Verticalia: muestra las imágenes de la ciudad vista pero desconocida", en La Verdad, n 33.028, 6 de marzo de 2008, pp. 64-65.

SOUGEZ, M.L. (2006): Historia de la fotografía (10 ed.). Madrid, Cátedra.

VÁZQUEZ CASILLAS, F. (2006): Historia de la fotografía en Murcia, 1975-2004. Murcia, Fundación Caja Murcia, Mestizo.

VILLENA, M. Á. (1990): «Dieuzaide: la fotografía puede captar detalles de la piel y del alma», en El País, no 4.801, 11 de junio de 1990.

Disponible en http://elpais.com/diario/1990/06/11/cultura/645055209_850215.html

WESTERBECK, C. y MEYEROWITZ, J. (1994): Bystander: a history of street photography. Thames \& Hudson. 


\section{Entrevistas con María Manzanera:}

MANZANERA. M., comunicación personal, 31 de marzo de 2014.

MANZANERA. M., comunicación personal, 19 de agosto de 2014.

MANZANERA. M. (5 de abril de 2017). Entrevista por Carmen Campos. Onda Regional de Murcia.

MANZANERA. M. Comunicación personal, 21 de abril de 2017. 
